\title{
Heavy Metal Analysis in Tai Lake Water Sample Based on Vanadium Oxide-Polypropylene Carbonate Modified Electrode
}

\author{
Shaofeng Shen ${ }^{1, *}$, and Yifei Zhang ${ }^{2}$ \\ ${ }^{1}$ College of Hydrology and Water Resources, Hohai University, No.1,Xikang Road, Nanjing, Jiangsu \\ Province, 210098, P.R China \\ ${ }^{2}$ Shanghai Smi Raw Water Co.,Ltd., No.1540, Beiai Road, Shanghai, 200125, P.R. China \\ *E-mail: shenshaofeng@mail.iap.ac.cn
}

doi: $10.20964 / 2016.07 .49$

Received: 10 April 2016 / Accepted: 22 May 2016 / Published: 4 June 2016

\begin{abstract}
Heavy metal ions are detrimental risks to human health due to their high toxicity. Electrochemical determination of heavy metal ions is an effective and low cost approach for environmental sample analysis. In this work, we prepared a vanadium oxide polypropylene carbonate for indium tin oxide electrode surface modification. The electrochemical property of the vanadium oxide polypropylene carbonate was studied cyclic voltammetry. The modified electrode showed an excellent performance towards detection of $\mathrm{Cd}^{2+}, \mathrm{Pb}^{2+}, \mathrm{Cu}^{2+}$, and $\mathrm{Hg}^{2+}$. The concentration measurement of heavy metal ions using proposed electrode are in good agreement with the previous reports. In addition, the proposed electrochemical sensor was applied for heavy metal content analysis of Tai Lake water samples.
\end{abstract}

Keywords: Heavy metal ions; Vanadium oxide polypropylene carbonate; Tai Lake; Electrocatalysis;

\section{FULL TEXT}

(C) 2016 The Authors. Published by ESG (www.electrochemsci.org). This article is an open access article distributed under the terms and conditions of the Creative Commons Attribution license (http://creativecommons.org/licenses/by/4.0/). 